\title{
Critical thinking in distance education: Developing critical communities in an audio teleconference context
}

\author{
TERRY D. ANDERSON* \& D.R. GARRISON** \\ *Extension Department, University of Alberta, Canada. \\ **Faculty of Continuing Education, University of Calgary, Canada.
}

\begin{abstract}
Distance education has long been associated with independent study and delivery of prepackaged learning materials. These characteristics effectively deny distance education students the opportunity to participate in communities of inquiry and, perhaps, opportunities to develop their critical thinking skills. This paper reviews the theoretical impact of socially situated learning, critical thinking and their implications for distance education. It then presents the results from a study of learners' perceptions while enrolled in two different models of audio teleconferenced delivered, university courses. The study reports quantitative results from a mail survey of these students and the qualitative results from interviews and classroom observations. The impact of the instructional design used by the delivering institution resulted in two distinct models of audio teleconference delivery with significant qualitative and quantitative differences in student perception. The paper concludes that leaming communities, which support the development of critical thinking skills, can be created at a distance and that they provide a mechanism for improving the quality of higher level distance education.
\end{abstract}

\section{Introduction}

This paper reports the results of an investigation of students' perceptions of learning in distance education courses delivered via audio teleconference (Anderson, 1994). The pervasive influence of instructional design on learning outcomes of mediated forms of educational delivery has been documented by many researchers (Clark, 1983). The traditional and dominant paradigm of instructional design in distance education has been prescribed course packages that ensure maximum independence. In recent years, however, low cost and accessible twoway communications technologies, such as audio teleconferencing, have given rise to important questions regarding the influence of instructional design on learning outcomes and perceptions. As a result the focus of this study was to explore the experience of learners exposed to the sustained, interactive learning environment created via audio teleconferencing in a credited university course.

\section{Review of the literature}

The study has been framed by research related to critical thinking and situated cognition. Distance education remains largely a private form of learning and little, if any, discussion in the distance education literature has focused on critical thinking or learning processes which are dependent upon social interactions. Thus, the following review focuses on critical thinking and situated cognition in education generally. 
Recent developments in learning theory have been aimed at integrating the cognitive and social environments in which learning takes place. Early researchers in cognitive development, such as Piaget (cited in DiPardo and Freedman, 1988), acknowledged that the social environment provides stimulus - through exposure to contradictory viewpoints or arguments - but still focused on individual cognitive growth and development. Though not denying individual cognitive development, Vygotsky (1978) argued that it is from within the social environment that the individual derives and develops individual cognitive processes. Learning takes place as individuals make sense of their experience within the social context. More recently, researchers interested in socially shared cognition (Resnick, Levine and Tesley, 1991; Rogoff, 1990), have argued that knowledge is created within, and is determined by, the social environment in which it is experienced. Notwithstanding the need for reflection, effects and implications of the social component of learning would appear to be important in many learning contexts, including those created at a distance. This is particularly true when studying ill-defined subject matter, common in the social sciences and humanities.

A number of social cognition theorists have investigated the importance of shared context in the learning process. Newman, Griffin and Cole (1989) looked beyond the individual as the basic unit of analysis when investigating cognitive development. Newman et al. (1989) noted that cognitive "construction work occurs as much in the interaction between the adult and the child as in the child's internal processes". They argued that learners appropriate new knowledge from other members of the group using the cultural aids of language and other forms of communicative interaction. The members of such groups do not need to have identical cognitive constructs or even shared understanding of the topics under discussion to create knowledge. Newman et al. (1989) postulated that "when people with different goals, roles and resources interact, the differences in interpretation provide occasions for the construction of new knowledge". This research, which emphasizes the social context of learning, provides support for educational systems that use the power and resources of the social group to expand and enhance learning. Conversely, (Newman et al., 1989) downgraded the effectiveness of individualistic learning by claiming that "cognitive change does not happen in a closed determined system". Earlier generations of distance education (Nipper, 1989) have been of this "closed, determined" type and thus have not supported the development of social cognition. The challenge to distance educators seems clear. In order to avail themselves of the learning opportunities presented by the social construction of knowledge, an opportunity for sustained interaction between and amongst learners and teacher is logically necessary.

\section{Community of inquiry}

There are a variety of indicators in the literature that support the notion that opportunity for sustained interaction between (amongst) student(s) and teacher is a significant precursor to the development of meaningful learning. Entwistle and 
Entwistle (1991) reported on study activities of undergraduates and concluded that "the negotiation of a shared meaning came out as one of the main strategies used to ensure that understanding was thorough". Deep or meaningful approaches to learning have been associated with affective involvement and satisfaction of intrinsic interest. Biggs (1990) wrote that "if the student's interest can be aroused then deep learning is likely to result". He provided examples of learning activities such as teacher's think-aloud modelling, peer-teaching, self-questioning and group projects as activities that require students to be self-insightful and, thus, affectively involved in the activities. The social nature of each of these suggested activities implies the necessity for sustained interaction between and amongst teachers and learners for the development of meaningful learning.

Schell and Branch (1993) argued that conversation, within the instructional process, is a necessary condition that ensures that participants share a common "understanding of each others knowledge and the specific context in which they find themselves". They contend that sharing unique cultural and cognitive perspectives, through conversation, enhances the potential for learner achievement. Therefore, the opportunity to engage with others (both peers and teachers) in a community of inquiry would appear to be an important component of deep or meaningful learning (Ramsden, 1988).

Critical discourse leads to deeper meaning and development of higher order cognitive skills in all subject areas. That is not to say, however, that the balance between reflection and critical discourse does not vary depending upon the object of study and the cognitive level of the participants. At the same time, we agree with Resnick (1991) who writes that "much of human cognition is so varied and so sensitive to cultural context that we must also seek mechanisms by which people actively shape each other's knowledge and reasoning processes".

Recent research in cognitive learning (Resnick et al., 1991) has illustrated that the social context or community which is created during the learning process has a large effect upon the nature of learning activities engaged in, the selection of content for study, and the learning outcomes. Similarly, Lipman, (1991) noted the crucial importance of community in formal education and in individual intellectual development. Lipman described the following characteristic behaviors of the community of inquiry:

- members question one another

- members request, of each other, reasons for belief

- members build upon one another's ideas

- members deliberate amongst themselves

- members point out possible counter examples to the hypotheses of others

- members utilize specific criteria when making judgement

- members cooperate in the development of rational problem-solving techniques

He viewed these characteristics as fundamental requisites for the development of higher level thinking. Lipman (1991) suggested that while the objective of critical reflection is intellectual autonomy, in reality, critical reflection is "thoroughly 
social and communal". This apparent paradox is explained by the fact that thinking is an attempt to understand or explain our experiences. Dewey (1959) rejected the separation of the psychological and social in the educational process. He believed that individual development is dependent upon community life. Reflective thought could not be separated from action. When action is separated from thought, teaching becomes a transmission of information without meaning. Critical reflection is an attempt to detach from the external world to construct meaning but the validity of that meaning is always grounded in experience. Discourse and reflection are essential aspects of the critical thinking process.

Exposure of students to these communities of inquiry is a crucial component of the educational experience. Lipman (1991) argued that cognitive acts and processes begin as adaptations to group behaviors and that thinking is "individual emulation of social norms and social conduct". There is, thus, a strong basis in recent cognitive learning theory for the inclusion of social interaction in the learning process, particularly in the creation of a critical community of learners. This community of inquiry is also considered to be essential in facilitating the development of critical thinking abilities.

\section{Critical thinking}

The opportunity to engage in and develop critical thinking has been considered a defining feature of higher education and of fully developed adult living (Brookfield, 1989). Entwistle and Entwistle (1991) found that "academic staff in higher education expect students to develop a conceptual understanding of their discipline, and to apply critical analysis to the information and ideas they encounter". McPeck (1981) suggested that education cannot be accomplished without critical thinking. Furthermore, Brookfield (1989) argued that critical thinking is essential outside of the adult classroom as well, and is characteristic of a "developed person". He noted that "the ability to think critically is crucial to understanding our personal relationships, envisioning alternative and more productive ways of organizing the workplace and becoming politically literate" (p. 14).

Arriving at a precise definition or even a simple conceptualization of critical thinking has proven to be a difficult task for a number of reasons. First, thinking itself is an internal process that currently defies all but indirect examination and observation. Second, the terms "thinking" and "critical" are each defined by popular connotations which generate considerable confusion. McPeck (1981) noted that "confusion stems from approaching the concept as though it were a selfevident slogan whose precise ingredients were considered to be clear and selfjustifying" (p.3). A number of educational philosophers have attempted to provide a more precise definition and practical understanding of this important component of the education process.

The adjective critical, when applied to thinking, should be considered as implying the need to lay clear the underlying premises upon which statements of facts, deductions, opinions or hypothesis are grounded. For Dewey (1933) the term 
"thinking" referred to a detachment from the external world in which contemplation and connections between ideas and facts can take place. Educational philosophers have described a variety of attributes which further define the concept. Dewey (1933) argued for including attitudes such as desire, will, passion and responsibility as components of critical thinking. Brookfield (1989) noted that critical thinking also includes commitment as well as "reflective scepticism". Thayer-Bacon (1993) added the quality of caring to the characteristics of the critical thinker. She believed that caring is as essential as reasoning and is the basis for developing trust and collaborative thinking. Thayer-Bacon also noted that her "rational model of [critical] thinking emphasizes people working together, each contributing his or her own perspective, and attempting to understand one another, to solve problems together" (p. 338). These social shared learning activities are necessary to "cross the barrier between self and other, bridging private and shared experience" (Thayer-Bacon, 1993). Critical thinking can be considered to be a process comprised of both individual internal activities and social or external activities.

A number of authors (Brookfield, 1989; Dewey, 1933; Garrison, 1991) have found it useful to describe critical thinking as consisting of a process made up of phases. Each of these authors have suggested that critical thinking phases are iterative and that the process often progresses in circular or spiral fashion with many iterations through the various phases or occasional jumps across phases.

Dewey's (1933) model of critical thinking, which he referred to as "reflective thought", is a generalized notion of the scientific method. He wrote that the five phases of reflective thought are: 1) suggestions, 2) problem definition, 3) hypothesis generation, 4) reasoning and 5) testing of the hypothesis. Brookfield (1989) added an important component to his description of the critical thinking cycle which consists of an integration phase in which newly developed notions are integrated into the existing fabric of our lives. However, Brookfield's model seems to have lost the evaluative or hypothesis testing component of the scientific method apparent in Dewey's model. Garrison's (1991) model takes the evaluative components of Dewey's model and includes Brookfield's integrative phase to develop a more comprehensive model of the critical thinking process. Most importantly for this study, Garrison also distinguishes between the reflective (private) and the collaborative (shared) activities which make up the process of critical thinking.

Garrison (1991) considered critical thinking to encompass problem solving and creative thinking and, thus, is fundamental to the development and application of education to practical life experiences of adult learners. Garrison's model of the critical thinking/learning cycle is composed of five phases - problem identification, problem definition, exploration, applicability and integration. This model was used as the basis for the development of the critical thinking items in the questionnaire component of this investigation.

The first phase of Garrison's model defines a state of curiosity or dissonance that serves as a triggering event that precipitates critical thinking. Once the problem has been identified the next step is to precisely define the problem. This may require assistance to critically examine our assumptions which may constrain thinking. The 
exploration phase is the search for possible explanations. Here one might be less critical and more open minded. The individual enters the reflective phase when ideas and concepts are assessed for their applicability. Finally, the result of the reflective process is tested through action and subsequent integration into the learner's thought processes and lifestyle. Through this process personal meaning is transformed into public knowledge. Invariably, the critical thinking process raises more questions that need to be explored through further interactions of reflection and action.

As noted previously, little attention has been given to the issues related to the support of critical communities of inquiry in distance education. Much of distance education has relied on independent study course materials, which provide little opportunity for critical discourse. There is, however, a fundamental shift in the perception and practice of distance education as having the potential to establish and facilitate critical communities of learners at a distance (Garrison, 1993). With the use of two-way communication technologies that do more than merely convey information, communities of learners can be created in which students consider alternatives, construct meaning, discuss discrepancies and develop consensual knowledge. How distance educators view learning and particularly the role of social interaction in learning, will be implicit in the design and delivery of the teaching-learning transaction at a distance.

This review underlines the importance of the learning community to the facilitation of critical thinking. Social interaction within supportive learning communities can be seen as essential in the development of communities of inquiry and critical thinking. Can this type of learning community be created at a distance using audio teleconferencing with its inherent lack of visual connection? The answer to this question, as perceived by student participants, was the focus of this investigation and the results are described in the following section.

\section{Method}

During the first phase of the investigation, an author-developed survey was mailed to 272 students, chosen at random from students enrolled in 23 distance education courses delivered by two Canadian universities. The courses were delivered from a number of faculties but the majority of courses were from the Social Science or Humanity disciplines. Audio teleconferencing was used in these courses to link students from 3-10 learning centres located in rural areas, with each other and with the instructor who was located at an urban university campus. The survey was completed and returned by $59 \%$ or 160 students. The survey questions were developed from Lipman's description of a "community of inquiry" (Lipman, 1991) and Garrison's discussion of the phases of the critical thinking cycle (Garrison, 1991).

The second phase of the investigation included 18 semi-structured interviews with students enrolled in teleconference supported courses. The students were chosen at random from those who attended the teleconferences. The one hour 
interviews were tape recorded and the transcripts analyzed with the aid of the Atlas/ti (Muhr, 1991) qualitative analysis tool. The interview schedule was developed after initial analysis of the survey data, thus providing an opportunity for the investigators to probe more deeply the individual perceptions of learning revealed collectively in the survey. To further triangulate data, the investigators observed 12 teleconference classes under field conditions. These observations coincided with the interviews and provided opportunity for the investigator to explore, in more depth, incidents and activities which were observed during the teleconference sessions. Finally, the authors mailed a summary sheet of the results of the investigation to all interview participants and conducted a focus group and seven individual telephone interviews which were used to confirm conclusions with the participants.

\section{Results}

The major discovery from the observations and interviews and confirmed by post hoc analysis of the survey data, was that the audio teleconference sessions were being used in two distinctive manners, each following a different instructional design model. These instructional design models permeated choice of learning activities, role of participants and the goals of the leaming process. The choice of instructional design was also correlated with significant differences in the capacity of the medium to support a community of inquiry and the development of critical thinking.

The two emergent design models are referred to as the "Community of Learners" (COL) and "Independent Learner Support" (ILS). Under a COL model, the teleconference technology was used (on a weekly basis) to support discussion, lecture, direct instruction, group activities and project presentations - much as an educational seminar is conducted with conventional face-to-face student-teacher interaction on campus. The COL model, through its capacity to allow student initiated discussion and content selection, encouraged creation of new knowledge which was integrated within the workplace context of teacher and learners. The following quotations illustrate the perception of learning experienced by COL students enrolled in courses that adhere to this model.

... and what we want to do when we're doing our section is, in fact, take advantage of all the people that have the information and get them to bring their experiences out and not be just reading off all the information that they could read themselves in the book. So the idea is to try to put some of ourselves into it as well, but the real resource that the people don't have access to, happens to be the opinions and thoughts of other people, so we have to incorporate that into it. I think that's essential for us. - (COL student)

I have been learning to become more reflective and discerning of subject matter, and of my own opinions and have been learning to accept the positions of others, because teleconference has explored their understanding and consequently encouraged me to change or reconsider my own. - (COL student)

Teleconference classes, developed under an ILS model, take place only once every two to four weeks and serve as an optional student support mechanism 
providing a pacing function and limited social learning support. The ILS model provides an opportunity for clarification and discussion of materials that have been presented in individual learning packages. The ILS model tends to support a surface approach to learning. Much of the discussion focused on satisfying institutional demands for passing the course. The learning activities using the ILS model, consisted in large part of teacher review of chapters from the text or study guide, discussion of assignments and tests, and answers to specific student questions. There was little use of discussion, debate, student presentation, guest speakers or other enrichment activities. This format, with its emphasis on didactic teaching and instrumental learning, seemed to meet the learning needs of many students as illustrated below:

For the most part, what I find helpful at those, is discussion of papers that are coming up, answering questions about content of them and exams. - (ILS student)

The odd time we're asked to do something extra to help you learn a little more or to help it stick a little more. I really hate doing them. Like I really only want to do the textbook, the notes, whatever. (ILS student)

There was also a group of ILS students who reported a strong sense of dissatisfaction with this model of instructional design. For these students, recapping of material that has already been read, without opportunity for application or further development, represented a waste of their learning time. This view is illustrated in the following quotations:

So, because the stuff is already in the textbook anyways . . . and on the tapes. I just find them [the teleconferences] redundant. - (ILS student)

Well, it's mostly answering questions from different students. I think I would enjoy it more if it was discussions. Like I would like to get into a discussion with people from other communities and see what they think about certain .... and make it pertinent to what's going on in our times right now. -(ILS student)

The following sections detail the quantitative differences in perception of learning by students studying using the identical technology, but very different instructional design models.

\section{Community of inquiry}

Characteristics of a community of inquiry were used to develop eight survey items (Lipman, 1991). Analysis of results showed significant differences between the two groups (COL and $\mathrm{LS}$ ) of audio teleconference learners using multivariate analysis of variance (MANOVA). That is, the two groups were compared and found to be significantly different on multiple quantitive measures.

Data (Table 1) illustrates the mean scores on each of the eight items. The COL students perceived the audio teleconferences as supporting the development of a community of inquiry to a greater degree than the ILS students on all eight items. On the three items most associated with social interaction (opportunity for in depth 
Table 1. Means on community of inquiry variables - Where 5 indicates strongly agree, 1 strongly

\begin{tabular}{llcccr}
\hline $\begin{array}{l}\text { Characteristics of Lipman's (1991) } \\
\text { community of inquiry }\end{array}$ & $\begin{array}{c}\text { COL Mean } \\
(\mathrm{n}=97)\end{array}$ & SD & $\begin{array}{c}\text { IS Mean } \\
(\mathrm{n}=97)\end{array}$ & SD & $\begin{array}{c}\mathrm{F} \\
(1,146)\end{array}$ \\
\hline $\begin{array}{l}\text { Provided input into what material is covered } \\
\text { during the course }\end{array}$ & 3.17 & 1.14 & 3.05 & 1.16 & .32 \\
$\begin{array}{l}\text { Provided feedback related to my leaming } \\
\text { Provided opportunity for in depth discussion }\end{array}$ & 3.69 & .94 & 3.54 & 0.97 & .70 \\
$\begin{array}{l}\text { Clarified my ideas by sharing them } \\
\text { Clarified my ideas by bearing other students }\end{array}$ & 3.82 & 1.06 & 2.88 & 1.13 & $13.41^{\cdots *}$ \\
$\begin{array}{l}\text { comments } \\
\text { Made me feel included in the class }\end{array}$ & 3.90 & .93 & 3.32 & 0.96 & $9.31^{* *}$ \\
$\begin{array}{l}\text { Provided feedback related to what others } \\
\text { think about my comments }\end{array}$ & 3.41 & .91 & 2.96 & 0.83 & $6.90^{\circ *}$ \\
$\begin{array}{l}\text { Provided an opportunity to develop } \\
\text { cooperative problem solving }\end{array}$ & 3.52 & 1.04 & 2.93 & 0.84 & $11.74^{* *}$ \\
\hline
\end{tabular}

$" p<.01, " * p<.001$

discussion; cooperative problem solving and feeling of inclusion in the class) the COL students perceived significantly greater opportunities to share in a community of inquiry. It is only on the items related to reception of feedback, comments of other students and opportunity for input into course materials that the differences between the two samples were not significant.

In summary, the survey data reveals that the COL students feel the audio teleconference technology supports the development of a community of inquiry. This community functions without the benefit of nonverbal communication channels used in face-to-face interaction, but the community of inquiry does operate - even when filtered through the teleconferencing medium. The significantly lower perception of a similar community of inquiry by ILS students illustrates that merely using the technology does not guarantee that a community of inquiry will be created. We see in these results the pervasive effect of different instructional designs on the perception of a community of inquiry. The design seems to override and dictate the approach of the teacher and the climate or culture of the learning community. To further explore the effect of design on the quality of learning we assessed the perception of opportunity to engage in critical thinking within the two instructional design models.

\section{Critical thinking}

Subjects were asked to rate their perception of opportunity to engage in 20 activities which are derived from the phases of Garrison's model of critical thinking (Garrison, 1991). This data was subjected to both descriptive and exploratory factor 
Table 2. Eigenvalues for critical thinking variables - community of learners sample

\begin{tabular}{cccc}
\hline Factor & Eigenvalue & \% of Variance & $\begin{array}{c}\text { Cumulative } \\
\text { \% of variance }\end{array}$ \\
\hline 1 & 8.9617 & 44.8 & 44.8 \\
2 & 1.7775 & 8.9 & 53.7 \\
3 & 1.2184 & 6.1 & 59.8 \\
4 & .9577 & 4.8 & 64.6 \\
5 & .8174 & 4.1 & 68.7 \\
6 & .7912 & 4.0 & 72.6 \\
7 & .7463 & 3.7 & 76.4 \\
8 & .6602 & 3.3 & 79.7 \\
\hline
\end{tabular}

analysis. The factor analysis of this data provided a conceptual mapping of the underlying dimensions of the critical thinking cycle perceived by the students and is used in comparison to the original conceptual model.

The data from both samples was analyzed by principal component factor analysis using SPSS programs. The data from the ILS suffered from a very low cases/item ratio and thus is not presented in this article. Principal component analysis with varimax (orthogonal) rotation of the COL data was first examined; however, the resulting solutions had some cross loadings on a number of variables and lacked a "simple structure." The correlation matrix for these variables was then rotated obliquely (Gorsuch, 1988), producing a solution that was simpler with only a single cross-loading of variables. The eigenvalues for the factors are presented in Table 2.

A four factor solution was chosen for its interpretability, despite the fact that the fourth factor had an eigenvalue less than 1.0. The three factor solution failed to clearly isolate the factor relating to applications of knowledge outside the formal class session. The COL solution had a small (.4000) cross loading on one item and one item which did not have a salient loading on any of the four factors.

Table 3 illustrates the factor solution chosen for interpretation with the salient factor loadings for each variable. Table 4 provides the factor correlations for the obliquely rotated factors.

The first factor, accounting for a high proportion (44.8\%) of the variance, has high loadings on those items associated with the applicability and exploration phases of the theoretical model. This factor is labelled the "exploration and critical evaluation" factor. The second factor ( $8.9 \%$ variance) loads on items related to the first phase of the critical thinking cycle, namely the identification of problems and stimulation of interest. This factor loads on all four items derived from the problem identification phase of the theoretical model and, thus, is labelled the "problem identification" factor. The third factor (6.1\% variance) loads on items related to defining learning outcomes, course objectives, and clarifying relevant personal problems. These items are all derived from the problem clarification phase of the theoretical model and, thus, the factor is labelled "clarification of course 
Table 3. Factor loadings of critical thinking variables - Oblimin rotation for COL sample

\begin{tabular}{|c|c|c|c|c|}
\hline Critical thinking item & $\begin{array}{c}\text { Critical } \\
\text { evaluation and } \\
\text { exploration }\end{array}$ & $\begin{array}{c}\text { Problem } \\
\text { identification }\end{array}$ & $\begin{array}{c}\text { Clarification of } \\
\text { course } \\
\text { requirements }\end{array}$ & $\begin{array}{l}\text { Integration and } \\
\text { application to } \\
\text { everyday living }\end{array}$ \\
\hline Disentangle ambiguities from text & .6841 & & & \\
\hline Test out ideas and solutions & .6593 & & & \\
\hline Develop new solutions & .5826 & -.4000 & & \\
\hline Explore new ideas and content & .5768 & & & \\
\hline Discuss concerns related to assignments & ts .5572 & & & \\
\hline $\begin{array}{l}\text { Critically evaluate the assumptions } \\
\text { and ideas of others }\end{array}$ & .5388 & & & \\
\hline $\begin{array}{l}\text { Encouraged critical assessment of } \\
\text { course content }\end{array}$ & .4991 & & & \\
\hline $\begin{array}{l}\text { Relate course content to previous } \\
\text { knowledge }\end{array}$ & .4756 & & & \\
\hline $\begin{array}{l}\text { Judge possible solutions to problems } \\
\text { and experience }\end{array}$ & {$[.3571]^{*}$} & & & \\
\hline Arouse interest in the course content & & -.7811 & & \\
\hline Trigger a desire to understand more & & -.7092 & & \\
\hline Understand issues thoroughly & & -.7051 & & \\
\hline $\begin{array}{l}\text { Made me aware of important } \\
\text { issues/problems }\end{array}$ & & -.6777 & & \\
\hline Identify interesting problems & & -.6680 & & \\
\hline Define expected leaming outcomes & & & .7801 & \\
\hline Clarify course objectives & & & .7785 & \\
\hline $\begin{array}{l}\text { Clarify relevant personal problems } \\
\text { related to the course }\end{array}$ & & & .5529 & \\
\hline $\begin{array}{l}\text { Apply course content to examples from } \\
\text { everyday living }\end{array}$ & & & & .8676 \\
\hline Assess the practical utility of new ideas & & & & .6810 \\
\hline Clarify problems at work & & & & .6406 \\
\hline
\end{tabular}

"Highest loading for item although not salient. Only loadings $<=.40$ shown.

requirements" factor. The fourth factor (4.8\% variance), loads on items related to application of knowledge from the course to the student's everyday life. This factor is labelled "integration and application to everyday life".

The factor analysis of the critical thinking variables, provided a solution that was to a large degree, isomorphic with Garrison's model. The confirmations and differences between the model and the factor analysis provide interesting insights into the perceptions of learning held by audio teleconference students and to the perception of critical thinking in this mediated educational environment. Of initial 
Table 4. Factor correlations for rotated factors - COL sample

\begin{tabular}{lcccc}
\hline Critical thinking item & $\begin{array}{c}\text { Exploration } \\
\text { and critical } \\
\text { evaluation }\end{array}$ & $\begin{array}{c}\text { Problem } \\
\text { identification }\end{array}$ & $\begin{array}{c}\text { Clarification of } \\
\text { course } \\
\text { requirements }\end{array}$ & $\begin{array}{c}\text { Integration and } \\
\text { application to } \\
\text { everyday life }\end{array}$ \\
\hline Exploration and critical evaluation & 1.000 & & & \\
Problem identification & .2975 & 1.000 & & \\
Clarification of course requirements & .3033 & -.1918 & 1.000 & \\
Application to everyday life & .3781 & -.3808 & .2695 & 1.000 \\
\hline
\end{tabular}

interest is the finding that the factors are not orthogonally related. Garrison (1991) noted in the discussion of the critical thinking model that there may be considerable overlap and iteration between the phases of the critical thinking cycle. Thus, the findings from this study, that the factors are more simply interpreted after oblique rotation, is not unexpected.

The major difference between the factor solutions and the model is the condensation of the exploration and applicability phases, proposed in the model, into a common factor that emerged in the analysis. Forcing of a five factor solution upon the data was investigated but did not produce clean separation of this factor as proposed by the model. Iteration between the exploration and applicability/ evaluation phases may occur frequently within the critical thinking process, as the participants discard exploratory solutions which fail tests of applicability and return to the exploration phase for a better solution. Garrison (1991) noted in his discussion of the applicability phase that "the individual may well return repeatedly to the exploration phase to generate a more satisfactory explanation, or as a check before proceeding to confirm and integrate the idea" (p. 194). This variance between the model and the factor analysis solutions does not, therefore, refute the model, but it does illustrate the iterative nature of critical thinking. The disparity between the five phases of the model and the four factors produced by the factor analysis may relate to the difficulty of applying this analytic tool, with its inherent search for distinct factors, upon a process described by most authors (Brookfield, 1989; Garrison, 1991; Thayer-Bacon, 1993) as being integrated and iterative.

The critical thinking model described the perception of critical thinking experienced in this environment, with increased attention to formal academic requirements. A factor called "clarification of course requirements" emerged in the analysis. This factor is related to the clarification stage proposed by the theoretical model, but is focused on clarifying course requirements, as opposed to more general subject related problems. This supports Ramsden's argument that assessment procedures have a profound influence on approaches to learning (Ramsden, 1992). He stated that "whatever we may say about our ambitions to develop understanding and critical thinking in our disciplines, it is our assessment practices and the amount of content we cover that demonstrate to undergraduate [and graduate] students what competence in a subject really means" (p. 72). External criteria (assignments, examinations etc.) are determining components of all activity in formal study 
(Entwistle and Entwistle, 1991). The emergence of this factor underlies the dynamic nature of critical thinking and the need to adjust any model of critical thinking to account for its differential development in various contexts. The formal academic environment has a built-in evaluation and assessment component that affects thinking at all stages and especially in the clarification stage.

It is important to recognize that it is not evaluation as such that influences and potentially distorts development of critical thinking skills. Our concern is the summative nature of the evaluation and the lack of opportunity for analysis and explanation of the results. While it is important that assessment goes beyond information recall and reflects a judgement of the depth of understanding, there should also be a process where teacher and students can re-construct concepts judged lacking in coherence or understanding.

Using variables from the critical thinking questionnaire a descriptive analysis was conducted. The two samples revealed interesting results as reported in Table 5.

Most importantly, for this study, the results illustrate that most of the students, in both samples, do perceive the audio teleconference as providing an opportunity for the exercise of critical thinking skills. MANOVA tests of difference between the two sample groups were significant (Wilks' criteria $F(5,133)=4.87 p<.001$ ) and subsequent ANOVA tests showed significant differences $(p<.01)$ between mean scores on each the 5 phases. In every case the mean score of the COL sample was higher then the ILS sample, indicating greater perception of the opportunity to engage in the development of critical thinking skills.

These results provide strong support for the notion that the development of critical thinking skills is perceived as possible, and is experienced by students enrolled in both models of audio teleconference supported distance education courses. However, those studying with a $\mathrm{COL}$ instructional design model had higher perceptions of opportunity to develop their critical thinking skills.

\section{Discussion}

Results from this investigation confirm that instructional designs which support sustained interaction between (amongst) student(s) and teacher enhance the

Table 5. Means for scores on the four items from each phase of the critical thinking cycle

\begin{tabular}{lccc}
\hline Phase of the critical thinking cycle & COL Sample & ILS Sample & F $(1,137)$ \\
\hline Problem identification & 16.27 & 14.39 & $17.77^{\cdots *}$ \\
Problem definition and clarification & 14.16 & 13.11 & $5.28^{*}$ \\
Problem exploration & 15.22 & 13.52 & $11.80^{* *}$ \\
Problem evaluation / applicability & 14.51 & 13.16 & $8.52^{* *}$ \\
Knowledge integration & 15.58 & 13.58 & $19.63^{\cdots *}$ \\
\hline
\end{tabular}

$p<.05 * p<.01 \cdots p<.001$ 
development of a community of inquiry and critical thinking. Data from this study confirms the increase in learner satisfaction and perceived meaningfulness of the learning experience through critical discourse.

Both the COL and ILS models of teleconferencing can serve useful pedagogical functions. The COL model was found to be more consistent with a model of education that stresses deep or meaningful learning which is consistent with critical thinking (Kember, 1991). The ILS model was not totally devoid of opportunity for critical thinking process, however, there were significantly less opportunities and encouragement for students to critically analyze the course content or their understanding or application of this content. Most of the interaction observed during the observations related to clarifying expectations and instructor rephrasing of materials previously presented in the course materials.

In a discussion of ways to improve teaching, Ramsden (1988) argued that teachers need to help students change their previous conceptions of knowledge. Merely telling students the "correct" conception usually does not lead to deep or meaningful learning because "change involves an active working upon and interaction between the old way of thinking and the new" (Ramsden, 1988, p.13). Independent study course materials, which are central to a generalized ILS model of teaching, imply that students' educational needs are for information acquisition. Therefore, it follows that information should be transmitted in a clear, logical and ordered fashion. There is little necessity for teachers to grapple with or necessarily be aware of students' pre-existing conceptions. It is assumed that new information, presented in the learning package, is correct and sufficient to meet learner needs. The students' task is to assimilate this information. Thus, the instructional design, which is embedded within the prescribed course content and delivery strategy, effects students' approaches to learning.

The participation and contributions of other students can lead to the development of a collaborative and critical approach to learning. The work and "real life" examples shared during the teleconferences were often mentioned by COL students, in the interviews, as major benefits of attendance at the teleconferences. Critical thinking is associated with integration of new concepts and ideas with previous knowledge and experience. This integration is facilitated by peer examples and illustrations of new knowledge application. Peer sharing during ILS model teleconferences generally focused on interpretations and questions relating to assignments, assessment activities, and clarification of subject matter introduced in the text or learning package. Although such exchange is valuable from an instrumental point of view (it enhances a student's potential to pass the course) it does little to develop critical thinking.

It is essential that teachers model and students be given the opportunity to experience a critical community of inquiry. There is an educational tradition stretching from Dewey (1933) to works by Brookfield (1989), Lipman (1991), Ramsden (1992) and others which are consistent with the COL model. This tradition has a well defined rationale for inclusion of interactive learning opportunities and the facilitation of critical discourse. The relevance of, and support for, interaction in the ILS instructional design model is less apparent. The 
interviews revealed that ILS students and teachers seemed unsure of the function of the discussion during the audio teleconferences and often fell back into activities that are defined exclusively by their relevance to the course package and evaluation criteria. This is not consistent with the often-articulated goal of higher education to develop critical thinking abilities (Ramsden, 1992). In order for the audio teleconference to assist learners in developing critical approaches to learning, instructional designers must build the teleconference into the distance learning system and not let it exist as an ill-defined, optional add-on.

The students who experienced the COL design model clearly identified and valued the critical thinking process and the opportunities for critical discourse. It is the critical community of learners that can encourage questioning and scepticism. To take the risk to challenge ideas and explore new conceptions and perspectives requires encouragement and support. For most students, development of critical thinking abilities is not facilitated very well or efficiently during independent study. As noted previously, critical thinking is the integration of thought and action. In an educational context, action is most often realized through critical discourse.

Although perceptions and practices with the distance education community are changing, this study raises questions regarding the traditional orthodoxy of distance education which is to provide as much freedom for students to study when and where they wish. Unfortunately, such independence provided by a variety of selfinstructional media provide little freedom regarding what and how to study. That is, much of the content is prescribed with little opportunity or encouragement to critically analyze, question or develop new ideas. The goal of such independent packaged learning is inevitably to assimilate the information as efficiently as possible in order to pass the exam. The evidence presented here indicates that distance education can do more than transmit information. Critical discourse recognizes "that knowledge is not static and it cannot be transmitted in whole from the teacher to the student" (Garrison, 1993). Furthermore, a critical community of inquiry and learning can be created at a distance using audio teleconferencing - if the instructional design goal is to do that.

\section{Conclusion}

The results of this investigation show that supportive learning communities can be created, at a distance, through the use of relatively low level technology - audio teleconferences. The opportunity for sustained communications between and among teacher and learners is crucial to the development of critical communities of inquiry. Distance education models which are based upon one-way media such as educational television, computer managed instruction, or text books, cannot be expected to facilitate a community of inquiry and, thus, will be less likely to provide opportunities to think critically. While some introductory and well defined courses will emphasize the presentation of basic information, it is argued here that some opportunity should be provided to support critical discourse and the development of a community of inquiry. 
Interactive audio teleconferencing sessions, developed under a community of learning model, can support university students in the development of meaningful approaches to learning and critical thinking. Merely using this technology does not, however, guarantee that such leaming communities will be created. Instructors and instructional designers must actively build in opportunity and reasons for sustained interaction amongst participants in order to support development of higher level thinking skills. Sustained interaction must be seen and experienced as an essential process, not as an adjunct, for a critical learning community to be developed at a distance.

The purpose of this research and the discussion is not to polarize distance education practice. In fact, the intent is to do the opposite. Critical thinking and discourse does not occur in a vacuum. Meaningful learning, based upon critical thinking and discourse, recognizes that information acquisition is important but insufficient. The Community of Learners design model should be seen as integrating information acquisition, critical reflection and critical discourse for the purpose of facilitating the construction of meaningful knowledge.

\section{Acknowledgements}

The authors wish to acknowledge the funding for the research associated with this investigation provided by the Northern Health Human Resources Research Unit at Lakehead University in Thunder Bay, Ontario, Canada.

\section{References}

Anderson, (1994). Socially shared cognition in distance education: An exploration of learning in an audio teleconferencing context. Unpublished $\mathrm{PhD}$ dissertation, University of Calgary.

Biggs, J. (1990). 'Teaching for learning outcomes', in Entwistle, N. (ed.), Handbook of Educational Ideas and Practice. London: Routledge, pp. 681-693.

Brookfield, S. (1989). Developing critical thinkers. San Francisco: Jossey-Bass.

Clark, R.E. (1983). 'Reconsidering research on learning from media', Review of Educational Research $53,445-460$.

Dewey, J. (1933). How we think. Boston: Heath and Company.

Dewey, J. (1959). 'My pedagogic creed', in Dewey, J. (ed.), Dewey on education. New York: Teachers College, Columbia University, pp. 19-32. (Original work published 1897)

Dipardo, A. and Freedman, S. (1988). 'Peer response groups in the writing classroom: Theoretic Foundations and new directions', Review of Education Research 58 (2), 119-149.

Entwistle, N., and Entwistle, A. (1991). 'Contrasting forms of understanding for degree examinations', Higher Education 22, 205-227.

Garrison, D.R. (1991). 'Critical thinking and adult education: A conceptual model for developing critical thinking in adult leamers', International Journal of Lifelong Education 10 (4), 287-303.

Garrison, D.R. (1993). 'A cognitive constructivist view of distance education: An analysis of teachinglearning assumptions', Distance Education 14, 199-211.

Gorsuch, R. (1988). 'Exploratory factor analysis', in Nesselroade, J. and Cattell, R. (ed.), Handbook of Multivariate Experimental Psychology. New York: Plenum Press.

Kember, D. (1991). 'Instructional design for meaningful learning', Instructional Science 20 (4), 289-310. 
Lipman, M. (1991). Thinking in Education. Cambridge: Cambridge University Press.

McPeck, J.E. (1981). Critical Thinking and Education. Oxford: Martin Robertson.

Muhr, T. (1991). 'Atlas/ti: A prototype for the support of text interpretation', Qualitative Sociology 14 (4), 349-371.

Newman, D., Griffin, P. and Cole, M. (1989). The construction zone: Working for cognitive change in schools. Cambridge: Cambridge University Press.

Nipper, S. (1989). 'Third generation distance learning and computer conferencing', in Mason, R. and Kaye, A, (ed.), Mindweave: Communication, Computers and Distance Education. Oxford: Pergamon.

Ramsden, P. (ed.), (1988). Improving Learning: New Perspectives. London: Kogan Page.

Ramsden, P. (1992). Learning to Teach in Higher Education. London: Routledge.

Resnick, L.B., Levine, J.M., and Teasley, S.D. (ed.), (1991). Perspectives on Socially Shared Cognition. Washington: American Psychological Association.

Resnick, L.B. (1991). 'Shared cognition: Thinking as social practice', in Resnick, L.B., Levine, J.M., and Teasley, S.D., (ed.), (1991). Perspectives on Socially Shared Cognition. Washington: American Psychological Association.

Rogoff, B. (1990). Apprenticeship in Thinking: Cognitive Developments in Social Context. New York: Oxford University Press.

Schell, N. and Branch, R. (1993). 'The role of conversation and culture in the systematic design of instruction', Educational Technology 23 (8), 7-18.

Thayer-Bacon, B.J. (1993). 'Caring and its relationship to critical thinking', Educational Theory 43, 323-340.

Vygotsky, L.S. (1978). Mind in Society, The Development of Higher Psychological Processes. Cambridge: Harvard University Press. 
http://www.jstor.org

\title{
LINKED CITATIONS \\ - Page 1 of 1 -
}

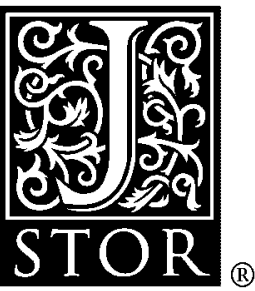

You have printed the following article:

\section{Critical Thinking in Distance Education: Developing Critical Communities in an Audio} Teleconference Context

Terry D. Anderson; D. R. Garrison

Higher Education, Vol. 29, No. 2. (Mar., 1995), pp. 183-199.

Stable URL:

http://links.jstor.org/sici?sici=0018-1560\%28199503\%2929\%3A2\%3C183\%3ACTIDED\%3E2.0.CO\%3B2-X

This article references the following linked citations. If you are trying to access articles from an off-campus location, you may be required to first logon via your library web site to access JSTOR. Please visit your library's website or contact a librarian to learn about options for remote access to JSTOR.

\section{References}

\author{
Reconsidering Research on Learning from Media \\ Richard E. Clark \\ Review of Educational Research, Vol. 53, No. 4. (Winter, 1983), pp. 445-459. \\ Stable URL: \\ http://links.jstor.org/sici?sici=0034-6543\%28198324\%2953\%3A4\%3C445\%3ARROLFM\%3E2.0.CO\%3B2-5 \\ Contrasting Forms of Understanding for Degree Examinations: The Student Experience and \\ Its Implications \\ N. J. Entwistle; Abigail Entwistle \\ Higher Education, Vol. 22, No. 3, Approaches to Learning and Perceptions of the Learning \\ Environment. (Oct., 1991), pp. 205-227. \\ Stable URL: \\ http://links.jstor.org/sici?sici=0018-1560\%28199110\%2922\%3A3\%3C205\%3ACFOUFD\%3E2.0.CO\%3B2-R
}

